\title{
PROMOTING SPIRITUALITY IN THE ARCHITECTURAL THOUGHT OF THE MOSQUE: A SENSE OF PLACE APPROACH
}

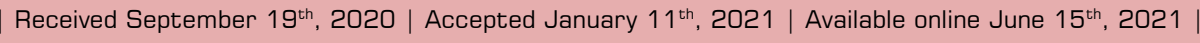

DOI http://dx. doi. org/10.18860/jia.v6i3.10303

\author{
Mahya Ghouchani \\ Department of Architectural Engineering, \\ Faculty of Semnan \\ Semnan Branch, Technical and Vocational \\ University (TVU) \\ Semnan Iran \\ m.ghouchani.arch@gmail.com
}

\section{Mohammad Taji}

Department of Mining Engineering

Shahrood Branch, Islamic Azad University

Zhahrood, Iran

mohammadtaji@yahoo.com

\begin{abstract}
This research aims to study the effects of meaning, body, and activity on increasing the sense of spirituality in a mosque. To this end, a descriptiveanalytic methodology was formulated in three stages based on the mutual relations between the independent variables of the structure's body and the dependent variables of mental concepts and activities. Initially, the pattern of people's movement from the entrance to the praying niche and the degree of proximity of the spaces were studied using the material flow patterns technique and the diagram for the relationship between activities. Then, the relationship between the ritual movements of the prayer and the mosque's architecture was analyzed. The magnitude of load in the human body caused by the movements in the prayer was measured using the OWAS technique. Finally, the spiritual moods and the meaningful concepts affected by light and color were analyzed based on the movement patterns of the prayers in the mosques. The results indicated that Islamic wisdom (including spatial order) directly affects and plays a significant role in determining the relationship between the mosque's various spaces and the mosque's structure in general
\end{abstract}

\section{KEYWORDS:}

promotion of spirituality, architecture of the mosque, sense of place, material flow pattern, OWAS.

\section{INTRODUCTION}

In the subject area of phenomenology, the sense of place is the truth of that place. In other words, it mainly refers to the spiritual characteristics of a place or its personality, which is close in meaning to 'the spirit of the place.' This means that the allure inherent in some places arises an indescribable feeling in individuals, making them enthusiastic, vigorous, and willing to return to those places [1]. It can be stated that the quality of an environment is the sum of these three components, each of which is responsible for improving one of the qualities of the environment. (Figure 1)

Reviewing the literature on the subject matter of the sense of spirituality, thinkers such as Nasr [2], Burkhart [3], and Naghizadeh [4] have qualitatively explained the concepts and hidden roots of spiritual emotions in the architectural body through a rereading of the mysteries, and transcendental wisdom inherent in Iranian-Islamic architecture. The discussions regarding holy ideas and holy mysteries have been addressed in most studies regarding mosques. The unknown and truths of the elements employed in the architecture of traditional mosques have been explicated qualitatively [5][6].

This approach is also seen in contemporary research on the subject of the mosque. Mahnaz Rei- eszadeh and Hossein Mofid, in An article entitled: "Mosques in urban architecture and amortization deviation of qibla," put a minor and recommended matter as the focus of research by making criterion it over positive experiences in responding to this problem in the Iranian mosques [7]. From this perspective, this article is a successful example of comparing religious experiences with physical principles. But it is not written down between this principle and other principles in architectural preferences. Abbasali Akhtari speaks about "Islamic mosques and orientation" on the values of unity and congregation among Muslims and uses religious texts to prove the necessity of mosques and the nature of the mosques or even the sub-physical characteristics which can affect the body has not mentioned [8]. Nader Karimian Sardashti, in the article "Maqsura in the mosque," wrote one of the few examples of the mosque's design critique based on religious texts [9]. After presenting a complete conceptualization of the glossary and identifying it in several themes in the architecture of the mosque, this article considers the interpretation of Maqsura, which refers to the enclosed room as the altar. It compares it with that of the religious texts, which has proved the injustice in the mosque. Mohammad Javad Mahdavinejad and Mohammad Mashayekhi, in the article "The design of the mosque based on socialcultural functions," analyzed the activity of the 
The structure of the mosque is based on the direction of the qiblah

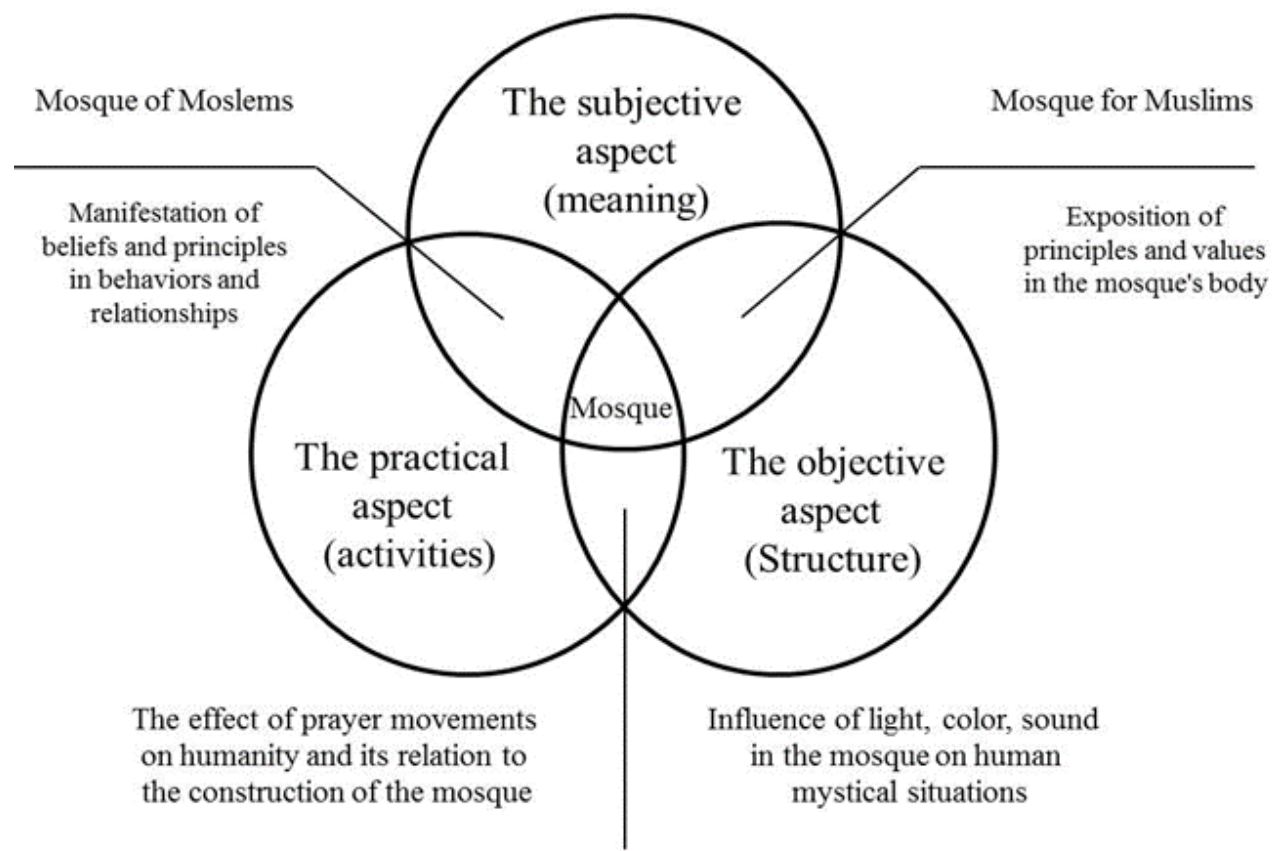

Mosque for worship

Manifestation of the mode of

worship in the body of the

mosque

Figure 1. The relationship between the three factors of human behavior, concepts, and physical characteristics of the mosque

prophet's mosque at the beginning of Islam and extracted the indicators as a criterion [10].

In this research, criteria have been derived based on the narrative and prophetic mosque design. Still, these functional attributes have been used as the standard of critique and analysis of the historic Iranian mosques. From this perspective, this article can be considered a successful example of applying religious principles in the study of the architecture of mosques. Mahdi Hamzenejad, in his doctoral dissertation entitled "Conceptual Principles and Applied Strategies in Architectural Design of Religious Buildings in Shiite Attitudes, Case study: Conceptual Differences in the Design of mosque, grave, and Mosalla." Referring to jurisprudence, to distinguish these three species, they extract the principles for their distinction from the point of view of the use of decorations [11]. Also, Hamzenejad, along with Ma'edeh Arabi, in the article "Examining the Islamic Essence of Iran in contemporary modern mosques," studies the case study of Tehran's Vali e-Asr mosque, wrote one of the few examples of the architectural critique based on religious texts [12].

Reviewing the literature on the subject, it can be understood that adaptation to the spirit of Islam is the most prominent feature of Islamic art, which can be found in the architecture of the mosque. Meanwhile, this paper aims to study the relational system of the standard components where a mosque is built as a holy place for the relationship between God and the individuals. Therefore, the current study looks for the answers to the following questions: (1) What are the effects of the mosque's design on spatial behaviors? (2) To what extent body-related signs and elements of the mosque can inspire individuals with a sense of place? (3) What are the effective factors for promoting "the sense of spirituality" and "the sense of place" in the architecture of the mosques?

\section{METHODS}

A descriptive-analytic methodology is formulated in three stages based on the mutual relations between the independent variables of the structure's body and the dependent variables of mental concepts and activities.

- The first step: The pattern of people's movement from the entrance to the praying niche and the degree of proximity of the spaces are studied using the material flow patterns technique and the diagram for the relationship between activities. The material flow is a path 
that materials, parts, people, information, and equipment move along to perform the manufacturing process leading to the final product. The entire issue regarding the material flow is that the elements (materials, parts, individuals, etc.) move in the best possible paths (in terms of the economy, safety, displaced distance, etc.) from the commencement of the work (the entry part) to the completion (the delivery part).

The Activity Relationship Chart (ARC) is almost the best technique for determining the relationship between the activities and different departments. This chart is used to analyze the relationship among all pairs of activities or departments. Thus, the degree of necessity of their closeness is recorded; then the sectors to be close to each other and those to be separated are identified. This chart can be applied in the following cases:

a. To determine the best initial arrangement of departments,

b. Showing the relationship between the different activities of a department and different departments,

c. An introduction to drawing up the activity relationship diagram [13].

In this chart, some qualitative symbols are used to specify the relationship of activities, and codes illustrate the reasons for these relationships. A classification of these qualitative symbols has been carried out by Richard et al. [14] Maitre regarding the importance of the closeness of activities. (Table 1)

Table 1. The degree of proximity of activities

\begin{tabular}{cll}
\hline Signs & $\begin{array}{l}\text { The degree } \\
\text { of } \\
\text { importance }\end{array}$ & \multicolumn{1}{c}{ Description } \\
\hline $\mathbf{A}$ & $\begin{array}{l}\text { Absolutely } \\
\text { necessary }\end{array}$ & $\begin{array}{l}\text { The closeness of the two places is } \\
\text { necessary. }\end{array}$ \\
\hline $\mathbf{E}$ & $\begin{array}{l}\text { Special } \\
\text { importance }\end{array}$ & $\begin{array}{l}\text { The close proximity of the two } \\
\text { places is very important. }\end{array}$ \\
\hline $\mathbf{I}$ & Important & $\begin{array}{l}\text { The closeness of the two places is } \\
\text { essential. }\end{array}$ \\
\hline $\mathbf{O}$ & Normal & $\begin{array}{l}\text { The closeness of the two places is } \\
\text { good. }\end{array}$ \\
\hline $\mathbf{U}$ & $\begin{array}{l}\text { not } \\
\text { important }\end{array}$ & $\begin{array}{l}\text { The closeness of the two places is } \\
\text { not essential. }\end{array}$ \\
\hline $\mathbf{X}$ & Undesirable & Being two places is better. \\
$\mathbf{X X}$ & Unfavorable & $\begin{array}{l}\text { Two places are necessary to be } \\
\text { distant. }\end{array}$ \\
\hline
\end{tabular}

A-related activities should be as close as possible; E-activities should be close, and I-activities should be nearly close to each other. Two activities may have an $X$ relationship due to the noise, the possibility of danger, etc. In addition, the codes that describe the reasons for the closeness of the activities are entered at the bottom of each cell. These numbers are inserted in a table below the chart with the degree of importance to make the reasons readable for the audience. (Figure 2)

- The second step: the relationship between the ritual movements of the prayer and the mosque's architecture is analyzed. The magni- tude of load in the human body caused by the movements in the prayer is measured using the OWAS technique. Karhu and Trapp, who worked in metal industries during the 1970s, developed a method for evaluating the working postures in work environments. This method is known as OWAS (Ovako Working posture Analysis System) and was introduced to the market between 1977-1981 by Karhu and Trapp. The basis of this method is a simple and regular categorization of bodily postures combined with the work execution through direct observation [15].

Using this method, the working postures and the loads on the skeletal-muscular system can be identified and categorized. Then, after identifying working postures, they can be prioritized and evaluated based on the information needed. Consequently, the work should be organized so that the number of body's inappropriate postures and the harmful static loads are reduced. In this technique, the body postures during the work are based on a coding system, and a 4-digit code recognizes each categorized posture, the numbers of which represent the postures related to the back, arms, legs, as well as the load or the effort required for doing the work. When adding up the posture codes, usage of a fifth digit is also possible, which indicates the working phase. In the following table 2, a combinational posture of those related to the back, arms, and legs is presented by researchers. (Table 2)

The practical categorization of the body postures during work and the resulting combination is as follows:

- The first group: the body posture and the combination of these postures during the work are normal and usual. Therefore, the resulting pressure on the skeletal-muscular system is acceptable, and there is no need for correction.

- The second group: the pressure resulting from the body postures or their combination slightly damages the skeletal-muscular system. Therefore, they should probably be corrected in the future.

- The third group: the pressure resulting from the body postures or their combination is harmful. Therefore, they should be corrected as soon as possible.

- The fourth group: the pressure resulting from the body postures or their combination severely damages the skeletal-muscular system. Therefore, they must be corrected immediately.

The combinational effect of the postures of the back, arms, and legs and the amount of force applied is considered based on the 4-digit OWAS code, and the priority of the corrections is determined

- The third step: the spiritual moods and the meaningful concepts, affected by the light and color, are analyzed based on the movement patterns of those saying their prayers in the mosque. 


Posture $\quad$ Code of every posture $\quad$ Description of the codes

Waist

EXAMPLE:
Back Posture: 2
Arm Posture: 1
Leg Posture: 6 $\begin{aligned} & \text { Code 1: Both arms are lower than shoulder height; } \\ & \text { Code 2: One of the arms is at shoulder height or above; } \\ & \text { Code 3: Both arms are at shoulder height or higher. }\end{aligned}$

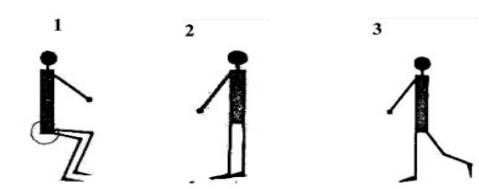

Code 1: Two free and dangling legs; Code 2: Standing with straight legs; Code 3: standing on one leg and straight;

Leg

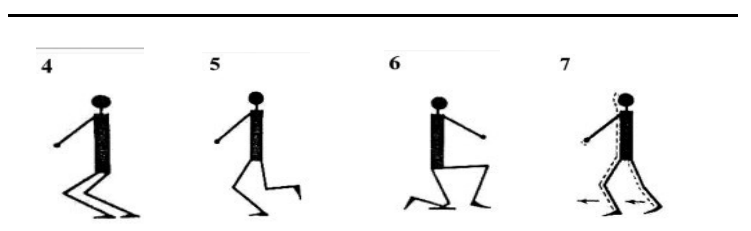

Code 4: Standing on two curved knees;

Code 5: Screwed on a curved leg;

Code 6: Squat on one or both knees;

Code 7: Walking or Moving.

\section{RESULT}

\section{THE OBJECTIVE ASPECT (STRUCTURE) OF THE MOSQUE IN} SPIRITUALITY

In mosques, the material flow refers to the way human moves from the entrance to the altar. This movement can be defined based on the material flow pattern as follows: the elements (individuals) should move in the best possible paths (in terms of creating a spiritual sense in humans) from the commencement of the work (the entrance part) to its completion (the altar and the Qiblah direction).

In addition to the functional, spatial, visual, and form hierarchy that can be identified in most traditional and religious buildings of the world, mosques also have other hierarchy levels in their ventricles which address more profound layers of human existence. One of these hierarchical aspects is the scheme that Iranian architects have used in the mosques to facilitate the confidentiality of presence in the divine mercy sanctuary.

The significance of Qiblah in contemporary mosques can be examined in two general categories:

1. The first category: mosques along the axis of the Qiblah;

2. The second category: mosques needed for rotation to amortize the Qiblah. From the analysis of this class of mosques, three types of entrances to the mosque are extracted: a) the entrance contrary to the direction of the Qiblah; b) the entrance through the front sides; c) the entrance through the end-half sides. Mosques along the direction of the Qiblah axis indicate that entering these buildings is done through the street and without mediation and any specific geometry, which is considered a significant disadvantage. There are two significant drawbacks in mosques with the entrance opposite the direction of the Qiblah. The first drawback is the lack of attention to the spatial axes such that not only is the entrance to the building not in the direction of the Qiblah axis, but it is also in the opposite direction of the divine direction. People enter the courtyard or dome without any mediation, and after entering, they turn towards the Qiblah direction with an unreasonable rotation. The second drawback is the lack of respect for the hierarchy of movements.

The architecture of mosques with the entrance in the front sides does not suffer a kind of rotation to deprecate the Qiblah axis so that while dealing with the problem of not paying attention to the spatial axes, a hierarchy of movement is achieved to put the material human in a secure and religious atmosphere to enter a spiritual space. However, the architecture of this class of mosques does lack a solid, regular, and 
D

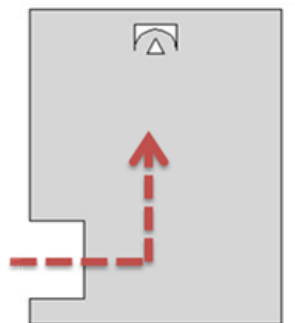

C

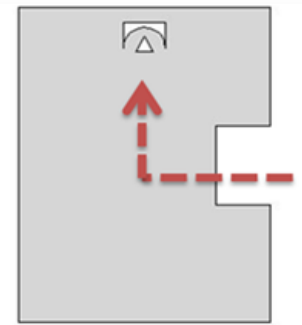

B

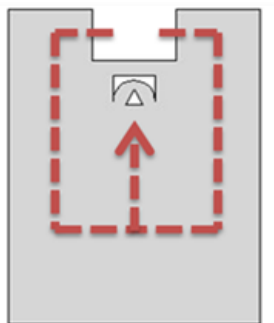

A

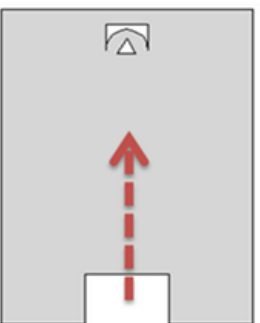

Figure 3. The route from the entrance to the Qiblah (A: Entering the direction of the Qiblah, B: Entering the opposite direction of the Qiblah, C: Entering through the sides of the side of the front, D: Entering through the half-ends of the sides)

meaningful geometry.

Similar to the mosques in the second category, the architecture of mosques with the entrances in the lateral sides of the end-half lacks any kind of rotation to deprecate the Qiblah axis so that while correcting the inappropriate spatial axes, the principle of the movement hierarchy is also observed to pass through a front space, reaching a mental readiness, leaving the material space, and placed in the direction of the secure divine sanctum. In terms of considering geometry, this category is similar to the second one. (Figure 3)

By using the technique of ARC, the relationship between the entrance spaces to the Qiblah and the degree of necessity of the proximity of each department to each other was examined, and an appropriate pattern was determined for putting these spaces together in the mosque plan, which is as follows:

At the entrance to the mosque, a man must pass through several spaces until he reaches the sanctuary and the axis of the Qiblah. These spaces include the frontage, doorway, vestibule, courtyard, porch, corridor, praying hall, and altar. Using the ARC, the relationship between each of these spaces and the degree of closeness of each part to each other was examined.

Reasons for the importance of spaces:

1. The sequence of working flow;

2. The relationship of individuals;

3. The usual route of movement;

4. The shared use of enclosure;

5. Noise, dust, cleanliness (purity). (Figure 4)

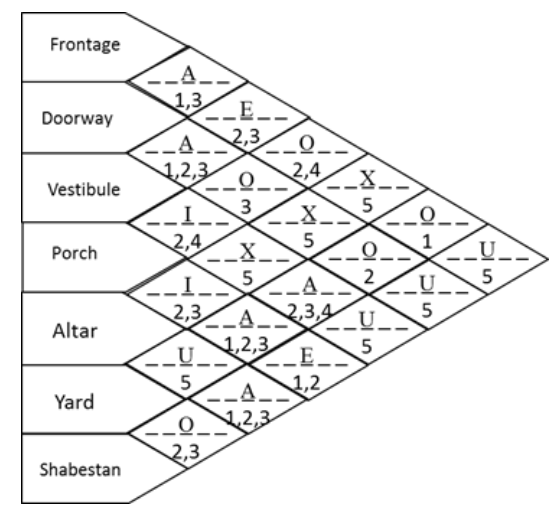

Figure 4. The relationship diagrams of the entry paths to the Qiblah in mosques
According to the ARC of the entrance to the Qiblah spaces in the mosques, the complete hierarchy of entry usually consists of seven components: the frontage is the first space that prepares humans to enter a space with different characteristics. After passing through the frontage, the audience must pass through the antechamber and the passageway. The antechamber is the station of disconnection from the world and is a little backward to its adjacent space. After the antechamber, the doorway passes the seeker (wayfarer) from the previous stages to the next ones. Following the passage of the doorway of the mosque, it leads to the vestibule. This space is different from the earlier spaces and stages. If the previous space calls the audience to pass through, this space calls for a pause in its geometric form.

After the vestibule is the hallway; the hallway refers to the theme of patience, and it is similar to struggling with self-righteousness. The hallway is usually a narrower and darker space than the vestibule. The hallway leads to the courtyard; the courtyard, due to its magnitude, reflects the soul's opening and expansion, leisure, and liberty. Then the porch is passed to reach the dome. The porch represents greatness and stretches upwards. The porch is also an introduction to the entrance to the dome. The greatness of the dome as the heart of the mosque calls for such an introduction, and the porch defines the authority of the importance of this space.

\section{THE PRACTICAL ASPECT (ACTIVITIES) OF THE MOSQUE IN SPIRITUALITY}

The modern knowledge that nowadays professionally addresses human-based designing is called ergonomics. The science mentioned above is considered one of the most critical issues in architecture. Ruskin believes that an architectural work can be understood using three ways. The first is through the discovery of the creative purpose; the second is via the analysis and deduction of the potentials of the building; the third is through the observer's reaction [17]. Ergonomics is a method that considers human needs, abilities, and physical and mental disabilities as central to the designing process so that their efficiency can be improved through comfort, security, health, and motivation [18]. 

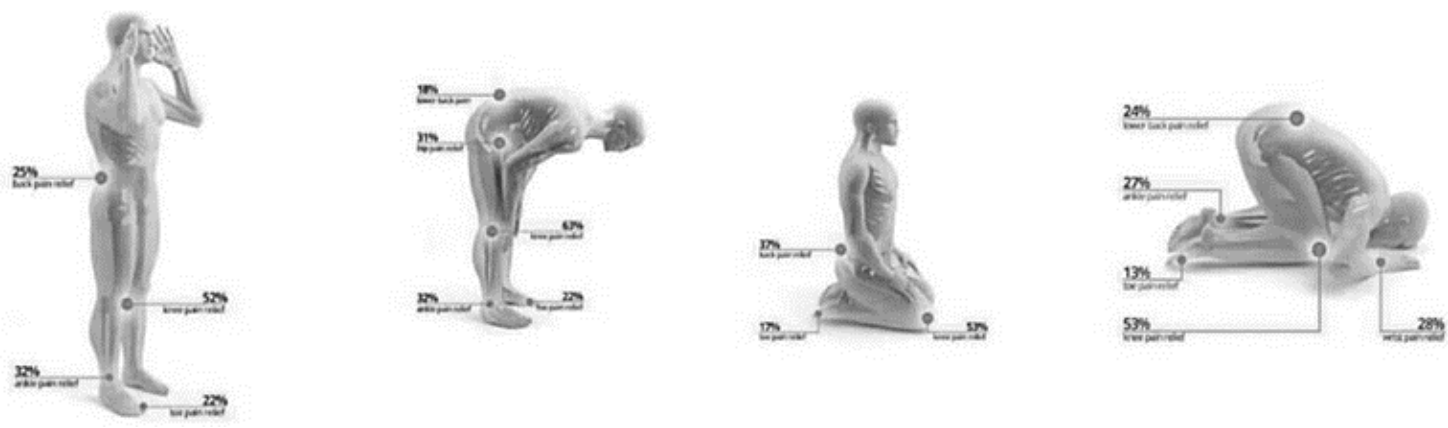

Figure 5. Sporting movements recommended by Dutch researchers

Considering the aspects such as physiology and psychology, the human being is a complicated being for whom the ways of achieving the highest level of satisfaction do not seem straightforward. On the other hand, possessing the two aspects of physiology and psychology, the environment also affects human beings. The latter factor addresses the type of activity done in the environment, where the environment should correspond with the activity performed in the place. If an individual doing the act of worship in a mosque is not provided with a place that helps his/her spiritual feelings, a place that is not solitary enough, or if there are hindrances to his/her concentration, they will not be satisfied with the act of worship and praying. Indeed, the environment should pave the way for a more intimate relationship between the worshipper and God instead of reflecting itself. This issue can be seen in the design of historical mosques but has been overlooked in modern mosques.

Recently, Dutch researchers have encouraged people to do exercises in sports centers similar to the movements seen in Islam's prayer. The athletic coaches of this country assert that the movements seen in Islam's prayer are beneficial to health. (Figure 5)
These pictures can be seen in Netherlands' public, and sports centers, and people are asked to do these exercises three times a day, 10 minutes each, accompanied by singing relaxing songs. However, these movements are those assigned by God to the Muslims. According to the above, the relationship between the spaces within the mosque, the ritualistic movements in the prayer, and the loads caused by these movements in the human body can be evaluated through the OWAS technique. (Figure 6)

Based on the results of the analysis, it can be stated that a complete set of exercises is employed in the prayer. The body posture during the acts of Ruku and Sajdeh may slightly damage the skeletal-muscular system since the spine is in a curved shape. Therefore, it is suggested that the elderly who cannot do these acts in the prayer correct their posture by saying their prayers in a sitting position. Different exercises have various benefits for the athletes; however, from God's point of view, a perfect set of practices is employed in the prayer. While the main point of concentration is worship itself, prayer is beneficial to health, so much so that European scientists have agreed upon this issue after 1400 years.

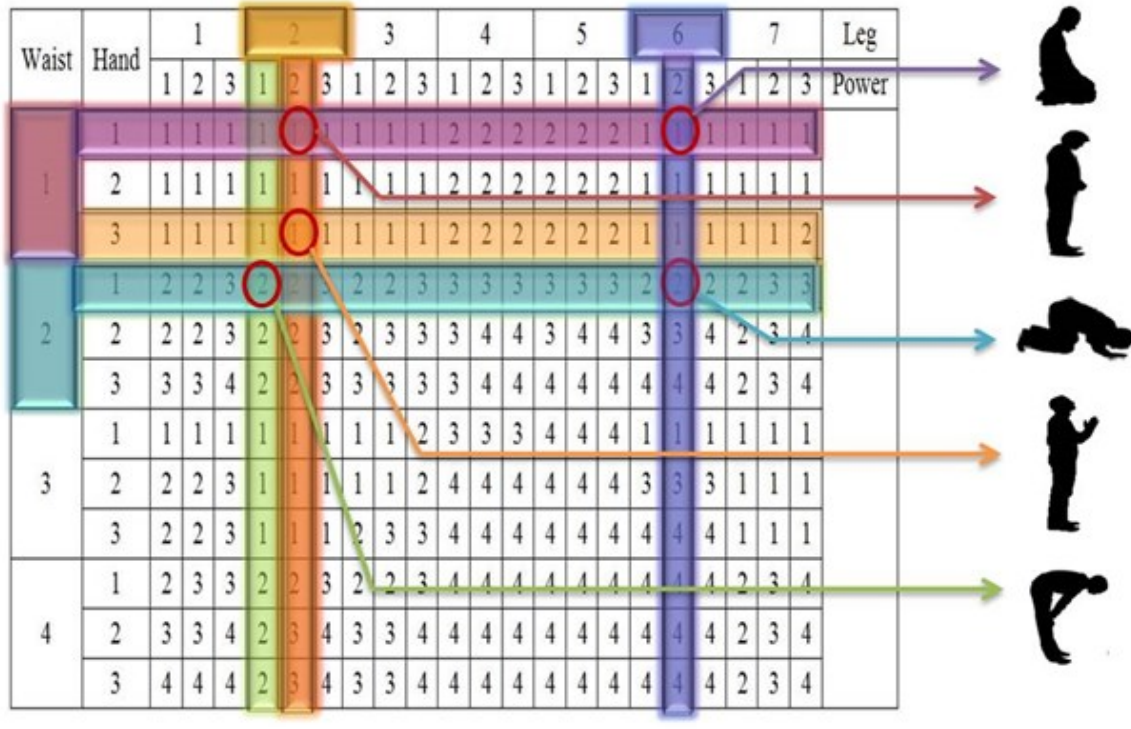

Figure 6. Owas analysis in prayer ritual movements
Tashahod, and Salaam Code: 1162

Qiyaam

Code: 1123

Sajdeh

Code: 2162

Qunut

Code: 1323

Ruku

Code: 2122 
tHE MENTAL ASPECt (MEANING) OF tHE MOSQUE IN SPIRITUALITY

In the history of Islamic art and architecture, the concepts of meaning and form have been closely intertwined. This is because in the Islamic worldview, the thought based on the unity of God forms the basis of Islamic art production. This relationship is seen in its utmost beauty and perfection in the mosque's architecture and the worship ritual of the prayer. Knowledge of the meaning leads to the recognition of God as the Almighty, leading to the understanding of the shapes. This process influences the creation of various spaces in the mosque's architecture, the employed drawings and paintings, the hierarchy of light, the number of decorations and ornamentations, sound, etc. [19]. The signs are the most structural elements in distinguishing a mosque from other structures. This shapes the picture of a mosque in people's minds through connection with the activities on the one hand and connection with the architectural design and spaces. The sequence of spaces in the mosques is formed hierarchically in three stages which are as follows [5]:

a. Detachment: emancipation from the material world.

b. Transformation: a space that plays the role of a connection between the material and spiritual worlds.

c. Joining: reaching the spiritual world and the holy nature of God. (Figure 7)

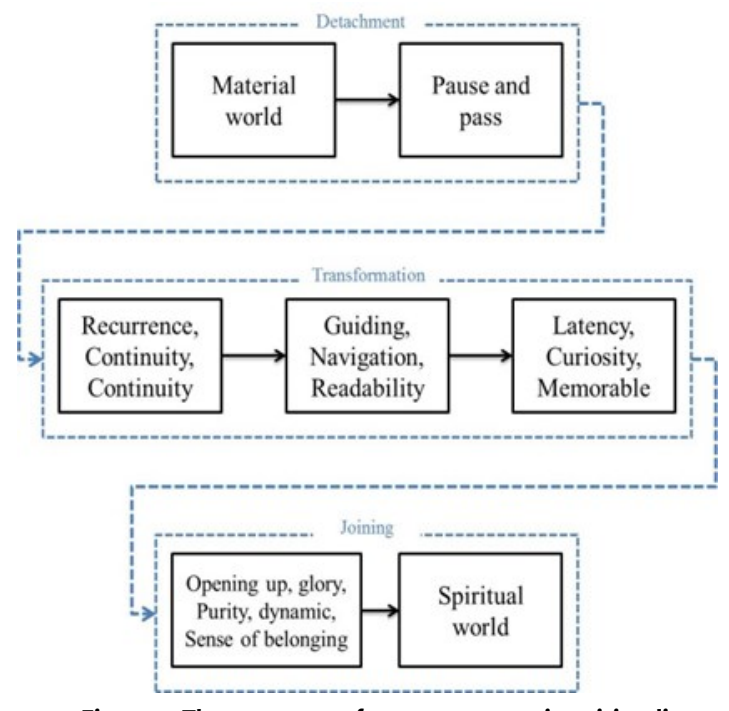

Figure 7. The sequence of mosque spaces in spirituality

Considering the common epistemology regarding form and meaning, the issue at stake is the human path towards the infinite. Therefore, it should be accepted that every step taken in the mosque must lead to human making and the divine way. From the external to the internal (from the material to the spiritual), this movement symbolizes the move from chaos to orderliness, from deficiency to perfection. Islamic mosques are manifestations of divine elegance and examples of the combination of the symbolic individual with divine beliefs. The symbolic patterns and relations can be seen in all aspects and symbols of the mosques [20].

\section{THE SEMANTIC MANIFESTATIONS OF LIGHT IN THE MOSQUE}

Light is the material form for the most significant voiceless force comprehended by the human senses, and we wish that it can preserve its mysterious point in the future [5]. Assuming light as only serving the purpose of making the material phenomena visible does not seem reasonable. On the other hand, it appears that a human willingness, whose symbol has always been the light, attracts him to this phenomenon. This can be vividly seen in the structures made with the permission of God the Almighty for the sake of worship. The purposes of using light in the architecture of the mosques are as follows:

Transparency and light reflection have always made the spiritless structure of the mosque more brilliant and beautiful. Combined with the spiritual values, this brilliance leads to the delicacy of this spiritual space. The creation of weak and robust penumbras lead to various sights based on the material used, with each having its nature. (Figure 8 )

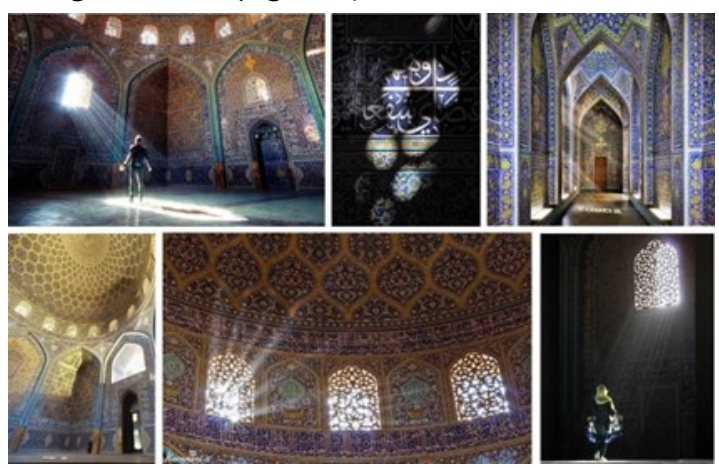

Figure 8. Mystical Reading of Light at Shaikh Lotfollah Mosque in Isfahan, Iran

Passing through transparent surfaces or via reflection, the light can significantly influence the spatial sense and establish itself as one of the most crucial elements in architecture. The use of porous surfaces and the creation of artistic penumbras on a surface may lead to a sense of lightness and suspension. The shades form elegant textures on a surface, and through making lighted, semi-lighted, and dark spaces, they can present a form of guidance and conscious play with the light. In the process of this playing with the light, beautiful spatial sights are formed on various surfaces.

\section{A SPIRITUAL READING OF LIGHT IN THE MOSQUE}

In Iranian art, colors are used wisely and consciously regarding their symbolic meanings and considering their effect on the soul through their combination and harmony. They are crucial to Iranian art, including architecture, where a complete understanding of their symbolic meanings is necessary for a deep 
understanding of Iranian art and architecture. The architects have used colors in mosques to make the colorlessness of praying evident, and provide the paththreader with a veil of color so that he is warned and made more vital during the act of worship. This is where the architects have sought colorlessness and have immersed the mosques in colors homogeneously through tile work. (Figure 9)

To enter the place, a prayer should free him/ herself from the material world; the colors used in this space realize this and provide the prayer with senses of modesty and belief, the consciousness of the internal, and the infinite. The prayer is then placed in an environment where specific combinations of colors allow for hesitation, meditation, and internal consciousness.

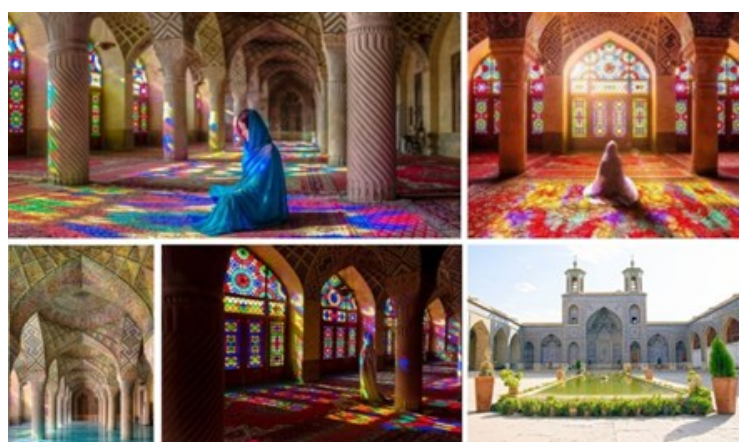

Figure 9. Mystical Reading Mystical readings of colors on Nasir Al -Malek Mosque, Iran

After that, as the prayer enters northern Iwan, his/her consciousness of the transience of the material world, as well as their belief, is strengthened. Entrance to the courtyard consolidates this aspect of the spiritual mood whereby the necessity of emancipation from the material world and achievement of the perfect faith is made vivid to the prayer. Finally, the prayer is positioned in a space whose combination of colors is a manifestation of the power and reality of the presence of God, a space full of mystery and ambiguity to raise the prayer spiritually in the presence of God.

\section{DISCUSSION}

If today's designers brood over the principles and criteria governing the formation of these metaphors and symbols, they can come to new conclusions, emancipate themselves from imitation, and build a space based on the needs of the modern man and the religion of Islam. This is since our traditional and holy spaces are replete with the innovations and creativities of their designers who, despite borrowing elements from the past, made them desirable for their time and the contemporary people and created an outstanding work of art. Therefore, the appropriate and successful pattern for designing today's mosques for the promotion of "the sense of spirituality," and based on the following criteria, is suggested as follows: (Table 3)
Table 3. The suggested pattern for the architecture of the mosque for the promotion of spirituality

\begin{tabular}{ll}
\hline $\begin{array}{l}\text { Components } \\
\text { practical on the } \\
\text { promotion of } \\
\text { spirituality in the } \\
\text { mosque }\end{array}$ & Suggested strategies \\
\hline The objective & $\begin{array}{l}\text { Emphasis on the direction of Qiblah; } \\
\text { following the hierarchy and spatial } \\
\text { discipline; creation of a balanced and } \\
\text { harmonious combination; utilization of } \\
\text { modern materials and technologies in } \\
\text { design; reproduction of holy concepts } \\
\text { and subject matters such as oneness, } \\
\text { orderliness, variety, spatial regulation, } \\
\text { hierarchy, accesses. in the structure and } \\
\text { physical features of the mosque }\end{array}$ \\
\hline $\begin{array}{l}\text { Observing the balance, beauty, and } \\
\text { dynamicity in design considering man } \\
\text { aspect (activities) }\end{array}$ & $\begin{array}{l}\text { and his needs; utilization of ergonomic } \\
\text { ratios; consistency of raising the prayer } \\
\text { and opening the mosque for people } \\
\text { during the day and night }\end{array}$ \\
\hline $\begin{array}{l}\text { Spatial purity and simplicity despite } \\
\text { mysteriousness and ambiguity; } \\
\text { employing natural elements such as } \\
\text { water for showing holiness and } \\
\text { reflection; using openings and windows } \\
\text { for shedding light in a way that it is not } \\
\text { only concentrated on a single point but } \\
\text { is present everywhere }\end{array}$ \\
\hline
\end{tabular}

The three indicators of sign, architectural design, and activity transform a structure into a mosque. The less the difference between these indicators, the stronger the sense of place will be. The effect of the structural design on the activities and emotions is an indirect one that occurs through signs and meanings

\section{CONCLUSION}

According to the research results, it can be said that the architectural criteria of mosques cannot be separated from each other. That is, the essence of God is seen alongside human, semantic, and formal standards. Paying attention to the nature of God in the architecture of mosques has created the same components. These components have given a beautiful variety to the architecture of mosques due to various reasons such as the architect's ability, climatic factors, and the ruling powers. The wisdom of Islamic architecture is that only by satisfying its appearance and body can it not find its way into its interior.

According to the view of Islamic wisdom, one of the essential features of mosque architecture is to give a physical aspect to the beliefs that are a crucial factor in the formation of architectural works. As a result, in the sacred architecture, which was directly influenced by religious beliefs, we can point to the existence of common points among the riddles of different religious buildings, which is the main factor in forming a sense of place in architecture.

The existence of elements and special spaces, alongside the signs and symbols, in the mosque - constantly used throughout history - plays an essential role in shaping the image of a mosque in the minds of the users. Furthermore, spatial relations and hierarchy are 
essential in the process of enriching the sense of the place. The appropriate functions and spaces for different activities provide the prayers with a sense of relaxation and pave the way for the act of saying the prayer more efficiently. We hope that re-identifying these hidden thoughts and their reproduction in designing today's mosques would guide the designers and architects in creating perfect and valuable works of art and lead human beings to their inner perfection, which is intimacy with God the Almighty.

\section{REFERENCES}

[1] L. Hosseinzadeh, Z. Raiesi \& F. Karimi, "An Analysis of the Sense of Location in Iranian Mosques and its Relationship with Human Being from the Point of View of Environmental Psychology (Case Study: Imam Isfahan Mosque)," Third International Conference on Applied Research in Civil Engineering, Urban Architecture and Management, University of Khaje Nasir al-Din Tusi, Tehran, 2015.

[2] H. Nasr, Art, and Spirituality, Translated by: Rahmati Inhallah, Art Academy, 2010.

[3] T. Burkhart. Islamic Art; Language and Expression, Translation of Massoud Rajabnia, Tehran: Soroush Publication, 2013.

[4] M. Naghizadeh, Islamic Architecture and Urban Planning (Theoretical Foundations), Isfahan: Rahian Publications, 2006.

[5] M.R. Bemanian \& M.A. Alinasab, "Investigating the role of light in explaining the sequence of mosque architecture (Case study: Sheikh Lotfollah Mosque, Isfahan)", Journal of Art Research, Vol 2, no. 4, pp. 71-82, 2012.

[6] J. Mehdi Nejad, H.R. Azamati, H. Sadeghi, \& A. Abadi, "Ranking of spirituality indices in the architecture of traditional mosques based on the perception of spirituality using the VIKOR method", Journal of Ontological Research, vol. 7, no. 14, pp. 59-82, 2018.

[7] M. Reiszadeh, \& H. Mofid, "Mosque in Urban Architecture and Deafness Deviation of the Qibla," Proceedings of the 2nd Architecture Conference of Mosque. Isfahan: Art University, 1999.

[8] A. Akhtari, "Mosques Construction and Islamic Approaches," Mosque Journal, vol. 81, pp. 6070, 2004.
[9] N. Karimian Sardashti, "Maqsura in the Mosque," Proceedings of the $1^{\text {st }}$ Mosque Architecture Conference. Isfahan: Art University, 1999.

[10] M. Mahdavinejad, \& M. Mashayekhi, "Designing mosques based on social-cultural functions," Armanshahr Journal, vol. 5, pp. 6567, 2010.

[11] M. Hamzenejad, Conceptual Principles and Practical Strategies in Designing the Architecture of Religious Buildings in Shia Attitudes (Case Study: Conceptual Differences in the Design of Mosque, Mazar and Mosala). Doctoral dissertation, Tehran: Library of the University of Science and Technology (Digital), 2011.

[12] M. Hamzenejad, \& M. Arabi, "Investigating the Islamic Originality of Iran in Contemporary Modern Mosques", Journal of Studies on Iranian-Islamic City, vol. 15, pp. 42-61, 2014.

[13] J.A. Tompkins, J.A. White, Y.A. Bozer, \& J.M.A. Tanchoco, Facilities Planning, United States: Wiley, 1984.

[14] R. Richard, B. Olery, \& K. Mutsonziwa, "Measurement Quality of Life in Informal Settlements South Africa", Social indicator research, vol. 81, pp. 375-388, 2007.

[15] H. Dabagh, Ergonomic study of work conditions in drilling and exploding mine openings and their comparison with each other, master's thesis, Islamic Azad University, Shahroud Branch, 2018.

[16] N. Fığlalı, A. Cihan, H. Esen, \& A. Fığlalı, "Image processing-aided working posture analysis: IOWAS", Computers \& Industrial Engineering, vol. 85, pp. 384-394, 2015.

[17] M. Hoomanirad \& A. Sharafinafar, "Conductivity in the Ergonomics and Spirituality of Daylight in the Architecture of the Mosques", Armanshahr, vol. 8, pp. 1-13, 2015.

[18] A. Jalali \& M.A. Rostaminejad, "Human Factors Engineering”, Eslah \& Tarbiyat, vol. 10, no. 108, pp. 44-53, 2011.

[19] H. Iman Talab \& S. Gerami, "The ratio of meaning and form (adaptation of thought architecture of the mosque and the formulation of prayer)", Islamic Art Studies Journal, vol. 16, pp. 77-88, 2012.

[20] R. Shaterian, Architecture Analysis of Mosques in Iran, Tehran: Nopardazan Publication, 2011. 